\title{
Estimating the Worldwide Volume of Counterfeit U.S. Currency: Data and Extrapolation
}

\author{
Ruth Judson \\ Richard Porter \\ rjudson@frb.gov \\ rporter@frb.gov \\ Division of Monetary Affairs \\ Board of Governors of the Federal Reserve System \\ Washington, DC 20551
}

September 2003

\begin{abstract}
The incidence of currency counterfeiting and the possible total stock of counterfeits in circulation are popular topics of speculation and discussion in the press and are of substantial practical interest to the U.S. Treasury and the U.S. Secret Service. This paper assembles data from Federal Reserve and U.S. Secret Service sources and presents a range of estimates for the number of counterfeits in circulation. In addition, the paper presents figures on counterfeit passing activity by denomination, location, and method of production. The paper has two main conclusions: first, the stock of counterfeits in the world as a whole is likely on the order of 1 or fewer per 10,000 in both piece and value terms; second, losses to the U.S. public from the most commonly used note, the $\$ 20$, are relatively small, and are miniscule when only counterfeit notes of reasonable quality are considered.
\end{abstract}

JEL Classifications: E49, C10 


\section{Introduction ${ }^{1}$}

In a series of earlier papers and reports, we estimated that the majority of US currency is in circulation outside the United States and that the share abroad has been generally increasing over the past few decades. ${ }^{2}$ Numerous news reports in the mid-1990s suggested that vast quantities of counterfeit dollars might be circulating overseas as well; these reports contrasted sharply with information from official sources indicating that counterfeiting is relatively rare. ${ }^{3}$ In this paper, we attempt to place an upper bound on the quantity of counterfeit in circulation

${ }^{1}$ The authors thank colleagues in the U.S. Secret Service Counterfeit Division, the Cash Function of the Federal Reserve Bank of New York, and the Division of Reserve Bank Operations and Payment Systems for assistance in compiling and obtaining data and for valuable discussions and comments. Members of the Divisions of Monetary Affairs and International Finance also contributed helpful comments. The views presented are solely those of the authors and do not necessarily represent those of the Federal Reserve Board or its staff.

2 Judson and Porter (2001), Porter (1993), Porter and Judson (1996), U.S. Treasury (2000, 2003), Porter and Weinbach (1999). Portions of the material here, which were written by the authors, appear in U.S. Treasury $(2000,2003)$.

${ }^{3}$ The reports of counterfeiting led to a congressional hearing on counterfeiting issues in February 1996, which resulted in a legislation requiring overseas audits of U.S. currency. (See "Counterfeit U.S. Currency Abroad: Observations on Counterfeiting and U.S. Deterrence Efforts," Statement of JayEtta Z. Hecker before the Subcommittee on General Oversight and Investigations, Committee on Banking and Financial Services, House of Representatives, February 27, 1996. In testimony leading up to this legislation, the GAO argued that the evidence about the true dimensions of the counterfeiting problem facing the United States overseas was mixed. In particular, the GAO could not verify the claims of the Treasury that the problem was economically insignificant nor those of Secret Service about the actual extent of the counterfeiting. In part because of these concerns, the Congress passed the Anti-Terrorism and Effective Death Penalty Act of 1996, which obligated the Secretary of the Treasury, in consultation with the interagency Advanced Counterfeit Deterrence group, see http://www.treasury.gov/offices/domestic-finance/acd/about.html, to make several reports to the Congress on the use and counterfeiting of U.S. currency abroad, including U.S. Treasury (2000, 2003). 
based on samples of counterfeit data collected by the Secret Service and Federal Reserve together with our understanding of circulation patterns for genuine and counterfeit currency. ${ }^{4}$ This paper differs from previous work in that the magnitude of the counterfeiting problem is examined for all denominations now being issued rather than just for $\$ 100$ s, as in our earlier work. ${ }^{5}$

We have very good sampling data from two sources that can be considered independent in various dimensions. In order to develop appropriate confidence bounds for extrapolation, we compare the data from these two sources. Both sources suggest that the incidence of counterfeits in the population is quite small, in the neighborhood of one note in 10,000 for the denominations now being issued. We are able to estimate the degree to which the currency received by the Federal Reserve System is likely to represent the total population of currency outstanding.

We conclude that it is unlikely that pockets containing large numbers of counterfeits can exist for very long outside the banking system, and that the total number of counterfeits circulating is at most a couple of times what the sampling data indicate. In particular, we find that an upper bound on the stock of counterfeit currency in circulation, as a share of genuine,

${ }^{4}$ The Treasury and Federal Reserve work together on currency design. Currency is produced by the Bureau of Engraving and Printing, a branch of the Treasury. The Federal Reserve distributes currency. The Secret Service, formerly a branch of the Treasury but as of 2003 a branch of the Department of Homeland Security, is charged with the responsibility of detecting and arresting any person committing any offense against the laws of the United States relating to currency. Since 1996, the Federal Reserve and Treasury have been legally required to provide estimates of genuine and counterfeit currency circulating outside the United States.

${ }^{5}$ Data coverage for the $\$ 2$ denomination is not as complete as it is for the other denominations, and so some of the analysis is not possible. However, the volume of $\$ 2$ notes in circulation is tiny, about 0.2 percent of the value of currency held outside banks. 
would still be less than 3 in 10,000. In addition, we present evidence that, for the denominations most commonly handled by U.S. consumers, the incidence of counterfeits that cannot be detected with minimal authentication effort is much smaller, on the order of less than one in $100,000$.

The paper proceeds as follows. The next section provides a brief overview of dollar usage outside the United States and counterfeiting within and outside the United States. Section 3 reviews the data sources that we use. The fourth section presents our estimates of the likely total value of counterfeit dollars in circulation. The fifth section presents estimates of how representative the notes that pass through the banking system are. The sixth section presents a model of currency circulation that demonstrates that it is quite unlikely that a large pool of counterfeits can circulate undetected. The seventh section concludes.

\section{$2 \quad$ Background}

Out of the approximately $\$ 630$ billion in U.S. dollars held outside banks at the end of 2002 , the Secret Service reported that about $\$ 40$ million in counterfeit currency was passed on the public ${ }^{6}$ While the loss associated with a counterfeit to the individual who mistakenly accepts it can be significant, the aggregate loss of $\$ 40$ million in 2002 amounts to about 15 cents per U.S. resident, a minor amount. Losses from counterfeiting have also been very small relative to the cost of check fraud and other forms of fraudulent transactions. For example, in 2002, the

${ }^{6}$ The Secret Service reported that additional quantities were "seized," or confiscated before they entered circulation. In this paper we focus on the figures for "passed" counterfeits. While seized notes posed some threat prior to the seizure, passed notes clearly caused losses to the banknote-using public. Moreover, the fact that they were passed at least once suggests that 
cost of check fraud to commercial banks was estimated to be nearly $\$ 700$ million, or nearly 20 times the cost of counterfeiting. ${ }^{7}$

\subsection{U.S. Dollar Usage Around the World}

The Federal Reserve supplies currency on demand. In practical terms, Federal Reserve Banks provide currency at face value to banks that have accounts with them. Banks that do not have accounts with the Federal Reserve can purchase currency through their correspondent banks that do have Federal Reserve accounts. Individuals and nonfinancial firms typically obtain currency from banks or currency exchanges.

As a share of the monetary aggregates, currency is relatively small: it makes up just over a third of the narrow monetary aggregate, M1, and about a tenth of the broader monetary aggregate, M2. However, there is a great deal of currency outstanding. Currency held outside depository institutions at the end of 2002 amounted to about $\$ 630$ billion, or about $\$ 2,200$ for every U.S. resident. ${ }^{8}$

Although a great deal of U.S. currency is in circulation per U.S. resident, not all U.S. currency is held within the United States. ${ }^{9}$ Cash U.S. dollars are used widely overseas. The U.S.

they passed a "quality control" by fooling at least one person.

${ }^{7}$ American Bankers Association, 2002. Other industry sources report that the overall losses from check fraud to consumers and businesses are in the range of $\$ 10$ billion per year.

${ }^{8}$ Weekly figures on the quantity of currency held by the public are reported on the H.6 report in Tables 4 and 7. The December 2002 not seasonally adjusted figure for the currency component, or currency outside U.S. Treasury, Federal Reserve Banks and the vaults of depository institutions, as shown on Table 7 , was $\$ 630.6$ billion

${ }^{9}$ The observations in this section are drawn from first-hand visits to dozens of economies by both authors over the past decade under the auspices of the International Currency Awareness 
dollar is the leading international currency in many regions, and our estimates from earlier studies suggest that between half and two thirds of all U.S. currency in circulation is held outside the United States..$^{10}$ People outside the U.S. have a wide range of motivations for holding and using dollars and a correspondingly wide range of habits for managing their dollar holdings. Generally, dollars are held when other assets are inferior in reliability, liquidity, anonymity, or compactness. In highly volatile economic and political conditions, dollars can virtually drive out other assets, including domestic currency. Moreover, once people lose faith in their local currency, they tend to hold dollars for a long time before the local currency is able to regain credibility. Beyond these situations, dollars are the currency of choice for travelers headed for destinations outside Western Europe, and are favored as a store of value or medium of transaction for large purchases in areas with moderate instability and underdeveloped financial services. U.S. currency provides individuals in these countries with a vehicle for savings and transactions that they would not otherwise have. For the U.S. taxpayers, there are benefits, too: total currency outstanding has yielded seignorage income of $\$ 20$ billion to $\$ 32$ billion per year in recent years, and the estimated portion of this revenue derived from overseas dollar holdings is in the range of $\$ 10$ to $\$ 20$ billion per year. ${ }^{11}$

Program run jointly by the Federal Reserve, U.S. Treasury, U.S. Secret Service, and Bureau of Printing and Engraving; see U.S. Treasury (2003), Table 3.1 for a list of countries visited. During these visits, the authors have spoken with literally hundreds of senior officials from central banks, commercial banks, cash handlers, and law enforcement agencies about currency usage and counterfeiting outside the United States.

${ }^{10}$ Judson and Porter (2001), Porter (1993), Porter and Judson (1996), U.S. Treasury (2000, 2003).

${ }^{11}$ For every dollar in currency obtained, individuals must give the Federal Reserve an asset worth 
For the purposes of this paper, we group currency abroad outstanding into three categories: currency hoarded, or held for long periods in one place; currency that circulates, but stays outside the United States and the banking system in general; and currency that is used largely for tourism or otherwise circulates back to the Federal Reserve through the banking system. The currency in circulation abroad that is most readily analyzed with existing data sources is that in the last category.

\subsection{The Economics of Counterfeiting}

Both theoretical studies and the little empirical information we have suggest that highquality counterfeiting is expensive and only effective when few counterfeits are passed relative to the amount of genuine currency in circulation. Producing high-grade counterfeits requires access to presses, inks, and high-grade paper. The last item is the most important element because cashiers and bank tellers often rely on touch to detect counterfeits. In addition, the notes must then be either passed or distributed to others for passing, which is a complicated undertaking when large volumes of notes are produced. A bank or an individual might be fooled into accepting a batch of counterfeits once, but it seldom happens more than that. Thus, the notes must be ever more widely dispersed. Informal discussions with the Secret Service indicate that the full cost of producing and distributing high-grade counterfeit $\$ 100$ s can be in excess of

a dollar. The Federal Reserve purchases Treasury securities with these assets. As long as the dollar remains outstanding, the Federal Reserve earns interest on its Treasury securities. Such interest earnings are rebated to the Treasury after deducting Federal Reserve expenses. In the four years from 1999 to 2002, the Federal Reserve returned between $\$ 23.7$ and $\$ 32.3$ billion to the Treasury each year (Economic Report of the President 2003, Table B-81.) 
$\$ 50$ per counterfeit. ${ }^{12}$

The few theoretical papers on currency counterfeiting also conclude that the only longrun equilibria are for very low or very high levels of counterfeiting. Lengwiler (1997) finds that in fact the only possible equilibria are for zero counterfeiting or a high level of counterfeiting. In his model, the equilibrium that actually occurs is a function of the note's production cost (i.e., difficulty of counterfeiting) and its face value. The monetary authority is more likely to invest in higher-cost notes and thus insure a zero-counterfeiting equilibrium the higher is the cost of counterfeiting and the higher is the value of the note. The U.S. dollar, especially its pre-1996 series, had significantly fewer counterfeit protection devices than many other industrialized countries and was relatively low in value. ${ }^{13}$ However, as Green and Weber (1996) point out, the technology embedded in the new-design 1996-series $\$ 100$ approached that of other countries' currency at that time. The technology of euro banknotes, which were introduced in 2002, is generally higher than the 1996-series U.S. dollar, but the new-design $\$ 20$ issued in October, 2003 has comparable security to the euro.

\section{Data Sources}

We have two primary sources of data from the Secret Service and the Federal Reserve. In addition, we have some institutional knowledge gleaned from both continuing contact and

\footnotetext{
${ }^{12}$ The fixed costs of producing high-grade counterfeits are relatively high. In addition, the costs of (successfully) passing more than a few notes into circulation can escalate quickly.

${ }^{13}$ The highest denomination now issued is $\$ 100$. In contrast, many other countries issue denominations valued between $\$ 500$ and $\$ 1,000$, and a few countries issue notes whose value exceeds $\$ 1,000$.
} 
periodic visits to banks, currency dealers, banknote shippers, and other officials responsible for currency distribution and counterfeit detection around the world. Both sources of data suggest that the incidence of counterfeiting among actively circulating U.S. banknotes is quite low.

\subsection{Secret Service Data on Counterfeiting}

The Secret Service is responsible for investigating, prosecuting, and preventing counterfeiting activity. They record counterfeit currency seized (i.e., found at the point of production, before it enters circulation) and passed (i.e., found in circulation) counterfeit currency by denomination, location, and production method. We focus on the data for notes passed for two reasons: first, only notes passed were ever in circulation; second, only passed counterfeits generate an economic loss to the public.

The Secret Service data are in principle complete, and should provide representative figures. That is, if twice as many counterfeits are found in Country X than in Country Y, one would in principle conclude that Country X had twice as many counterfeits as Country Y. However, these data are incomplete for two major reasons. First, while U.S. law requires that all counterfeits be turned over to the Secret Service, local treatment and reporting of counterfeits outside of the United States varies considerably. Counterfeit U.S. dollars found abroad may be retained by banks, returned to customers, or held by local law enforcement authorities without being reported to the Secret Service. In some countries, counterfeiting of foreign currency is not illegal, or counterfeits presented at banks or exchange offices are routinely returned to the holder or retained by the bank or exchange office. Teams from the Treasury's International Currency Awareness Program (ICAP) visit banks and other cash handlers in various countries, and when 
teams visit it is not at all uncommon for the banks visited to produce substantial caches of counterfeits that they have accumulated and held, either because they wish to use the notes to train their cashiers or because, prior to meeting the Secret Service agents, they had little idea that the Secret Service considers it useful to at least examine and ideally retain passed counterfeits for investigative purposes. The banks are not necessarily obligated to turn the counterfeits over to the Secret Service. Second, the capacity of the Secret Service itself to detect and seize counterfeit U.S. currency overseas is directly related to its ability to develop working relationships with the appropriate agencies and officials overseas--detection of counterfeits is generally higher in countries in which the Secret Service has better ties with local law enforcement agencies. As shown in the top panel of Table 1, in fiscal year 2002 the Secret Service recorded $\$ 42.9$ million in counterfeit currency passing in the United States, but only $\$ 1.4$ million in passing activity outside the United States. Because of the reporting and data problems described above, the Secret Service agrees that the true quantity of U.S. notes passed abroad is considerably larger than the reported quantity and is likely similar in magnitude to U.S. passing activity. $^{14}$

${ }^{14}$ U.S. Treasury $(2000,2003)$. 


\begin{tabular}{|c|c|c|c|}
\hline \multicolumn{4}{|c|}{$\begin{array}{c}\text { Table 1 } \\
\text { 2002 Data on Counterfeits } \\
\text { Millions of dollars except as noted }\end{array}$} \\
\hline \multicolumn{4}{|c|}{$\begin{array}{c}\begin{array}{c}\text { Counterfeiting Activity Reported to the U.S. Secret Service, Fiscal } \\
\text { Year } 2002\end{array} \\
\end{array}$} \\
\hline & Domestic & Foreign & Total \\
\hline Counterfeit $\$ 100$ s passed & 33.9 & 1.3 & 35.2 \\
\hline Counterfeit $\$ 100$ s seized & 8.1 & 117.0 & 125.1 \\
\hline All counterfeits passed & 42.9 & 1.4 & 44.3 \\
\hline All counterfeits seized & 9.7 & 120.4 & 130.1 \\
\hline \multicolumn{4}{|c|}{$\begin{array}{l}\text { Counterfeits Detected in Federal Reserve Processing, Calendar Year } \\
2002\end{array}$} \\
\hline & Domestic & Foreign* & Total \\
\hline Counterfeit $\$ 100$ s detected & 4.27 & 0.73 & 5.00 \\
\hline All counterfeits detected & n.a. & n.a. & 7.01 \\
\hline $\begin{array}{l}\text { Detection rate for counterfeit } \$ 100 \mathrm{~s} \text {, } \\
\text { notes per million }\end{array}$ & 33.6 & 20.4 & 30.7 \\
\hline $\begin{array}{l}\text { Detection rate for all counterfeits, } \\
\text { notes per million }\end{array}$ & n.a. & n.a. & 5.0 \\
\hline
\end{tabular}

\subsection{Federal Reserve Processing Data}

Each of the roughly three dozen Federal Reserve Cash Offices collects data on its cash processing activities, including counterfeit detection. These data are useful in three ways. First, the Federal Reserve Bank of New York, which is the major port of entry and exit for overseas shipments of U.S. dollars, can often identify the source country of the counterfeits it receives. These data complement the data collected by the Secret Service in several respects. First, these 
data measure counterfeiting in dollars that circulate differently. The Secret Service data cover notes that were detected abroad, or, in the taxonomy mentioned in the introduction, are circulating but remain outside the Federal Reserve. The Federal Reserve data, in contrast, capture notes that by definition have been returned to the United States. Thus, the correlation between these two sources can be used to calculate confidence bounds for the population of notes in circulation as a whole.

The second use of Federal Reserve processing data for this paper comes from the fact that separate statistics are recorded for pre-1990 series notes, 1990-series notes, and 1996-series notes. ${ }^{15}$ Notes circulating within the United States are likely to return to Cash Offices more quickly, while overseas notes in remote areas and areas where dollars are used more as a store of value than as a medium of exchange are like to circulate to Cash Offices only infrequently. ${ }^{16}$ The information on the series status, however, can be exploited to obtain estimates of how much of the total currency population is in "active" circulation and how much might be hoarded.

The third use of Federal Reserve processing data is the most direct: from counterfeit detection rates and total processing figures, we can estimate confidence intervals for the true

${ }^{15} 1990$-series notes were first issued in 1991 and include a security thread and microprinting. 1996-series notes were first issued in 1996 and include a larger portrait, a reflective security thread, a watermark, additional microprinting, optically-variable ink, and other features to prevent counterfeiting. A 2004-series \$20 design was unveiled in May, 2003.

${ }^{16}$ Depository institutions bear the cost of transporting currency for deposit in Federal Reserve Banks. For U.S. depository institutions, the volumes of currency are typically relatively large and the nearest Federal Reserve Bank is typically not very far away, so the transportation costs are relatively minor. For overseas institutions, however, the costs of transporting currency to the nearest Federal Reserve Bank can be considerably higher, providing an incentive for these institutions to try to recirculate currency rather than return it. 
incidence of counterfeits among the stock of dollars circulating actively.

\subsection{Institutional Information}

The final sources of information, but not hard data, are the observations made during the International Currency Awareness Program's visits to dollar-using countries, in which both authors have participated. Locations visited by the authors of the current paper included Argentina, Bahrain, Belarus, Bolivia, Bulgaria, Chile, China, Colombia, the Dominican Republic, Ecuador, El Salvador, Egypt, Greece, Hong Kong, Latvia, Lithuania, Mexico, Panama, Peru, the Philippines, Poland, Romania, Russia, Saudi Arabia, Singapore, South Africa, Switzerland, Taiwan, Turkey, United Arab Emirates, the United Kingdom, and Vietnam. Other team members visited Brazil, Cambodia, Indonesia, Japan, South Korea, Paraguay, and Thailand. In addition to providing a great deal of information about how and why U.S. currency circulates in other countries, discussions during ICAP team visits indicate that most currency returns to the banking system with surprising regularity, that internal counterfeit detection statistics at commercial and central banks worldwide fall into a fairly narrow and low range, that counterfeit detection skills are remarkably high wherever dollars are used, and that counterfeit detection practices are very responsive to market forces. ${ }^{17}$

\section{$4 \quad$ Estimating the Total Quantity of Counterfeit Dollars in Circulation Worldwide}

The worldwide estimates of counterfeiting rely on a variety of data sources with differing

\footnotetext{
${ }^{17}$ Banks displayed varying counterfeit detection practices depending on local labor costs, local counterfeiting activity, and the relative cost of missing a counterfeit.
} 
characteristics. Specifically, we have made three sets of calculations to estimate the total amount of counterfeit currency now in circulation. First, we generate a lower bound for the total number of counterfeits by denomination based on Federal Reserve cash processing data. Second, we generated an upper bound for counterfeits by denomination by extrapolating from Federal Reserve data to cover counterfeits found outside the Federal Reserve. Third, we generate a range of plausible estimates for all denominations based on the relative incidence of $\$ 100$ counterfeits and lower-denomination counterfeits. We conclude that the total value of counterfeits in circulation at any moment is on the order of $\$ 40$ to $\$ 50$ million, or less than $\$ 1$ for every $\$ 10,000$ outstanding, and is highly unlikely to exceed $\$ 108$ million, or less than $\$ 2$ for every $\$ 10,000$ in circulation. Further, we conclude that the incidence of counterfeits is roughly the same inside and outside the United States, and thus the distribution of counterfeits follows the estimated distribution of genuine currency, which is estimated to be about 55 to 60 percent abroad with the remainder located within the United States.

\subsection{Estimating the Minimum Stock of Counterfeits in Circulation}

The Federal Reserve keeps records on the origin of counterfeit U.S. notes it detects.

However, as a basis for comparison, the exact amount of U.S. currency held abroad is unknown.

To take account of the possibilities, we use a broad range of assumptions on the share of total U.S. currency held abroad. For shares of $\$ 100$ s held abroad from 40 percent to 70 percent, Table 2 presents the counterfeit detection rate per million notes and the implied value of counterfeit 
notes. ${ }^{18}$ The Federal Reserve processing data suggest that the total stock of $\$ 100$ counterfeits outstanding is in the range of about $\$ 11$ million to $\$ 13$ million, a figure we consider a lower bound for several reasons. First, the notes sent to Federal Reserve Cash Offices are a relatively "clean" sample of the population of all notes in circulation because such notes have already passed through several detection "screens" before reaching the Federal Reserve. If a counterfeit is deposited at a commercial bank, the probability that it will remain in the stock of notes sent on to the Federal Reserve is less than 1, and most likely substantially less than 1. Four possibilities for disposal await a counterfeit that arrives at a commercial bank. First, if undetected it could be recirculated or sent to the Federal Reserve. In the latter case, it would appear in the Federal Reserve processing data. ${ }^{19}$ Second, it could be detected as a counterfeit by the bank, and reported to the police and Secret Service. In this case, the note would appear in the Secret Service's statistics but not in the Federal Reserve's statistics. Third, it could be detected and returned to the depositor (although virtually no U.S. banks return suspected counterfeits to depositors). ${ }^{20}$ Fourth, it could be detected and confiscated but either not reported to the police and Secret Service or not released. Banks are often eager to retain a few counterfeits for use in training their own tellers. In some countries, banks are permitted to report counterfeits and then

\footnotetext{
${ }^{18}$ Although the estimates in Porter and Judson (October 1996) and U.S. Treasury (2000, 2003) put the estimated overall share of currency abroad between 55 and 70 percent, Feige (1996) presents estimates as low as 40 percent.

${ }^{19}$ It is assumed that the Federal Reserve detects all counterfeits in shipments it receives. For a discussion of this assumption, see Allison and Pianalto (1997).

${ }^{20}$ Nearly every central bank in the world, including the Federal Reserve, forbids this behavior on the part of local banks and currency exchanges, but some evidence and the ICAP teams' interviews suggest that it occurs with some regularity outside the United States.
} 
retain the notes. This set of notes thus does not appear in the Federal Reserve statistics but may or may not appear in the Secret Service statistics. Counterfeit detection at commercial banks is generally quite good, so we believe that the majority of counterfeits that arrive at banks do not get shipped to the Federal Reserve. The observation that the Secret Service receives five times as many passed counterfeits as the Federal Reserve would seem to bear this out.

\begin{tabular}{|c|c|c|c|}
\hline \multicolumn{4}{|c|}{$\begin{array}{c}\text { Table } 2 \\
\text { Counterfeit \$100 Stocks Implied by } 2002 \text { Federal Reserve Processing Data } \\
\text { Assuming Varying Shares of Currency Held Abroad }\end{array}$} \\
\hline Location & $\begin{array}{c}\text { Detection rate } \\
\text { (notes per million) }\end{array}$ & $\begin{array}{l}\text { Value of genuine notes held in } \\
\text { location based on assumption } \\
\text { (billions of dollars) }\end{array}$ & $\begin{array}{l}\text { Implied counterfeits } \\
\text { (millions of dollars) }\end{array}$ \\
\hline \multicolumn{4}{|c|}{ Assuming 40 percent of $\$ 100$ s held abroad } \\
\hline Domestic & 33.6 & 276 & 9.3 \\
\hline Foreign & 20.4 & 184 & 3.8 \\
\hline Total & $\ldots$ & $\ldots$ & 13.1 \\
\hline \multicolumn{4}{|c|}{ Assuming 70 percent of $\$ 100$ s held abroad } \\
\hline Domestic & 33.6 & 138 & 4.6 \\
\hline Foreign & 20.4 & 322 & 6.6 \\
\hline Total & $\ldots$ & $\ldots$ & 11.2 \\
\hline \multicolumn{4}{|c|}{$\begin{array}{l}\text { Note: Stock of } \$ 460 \text { billion in } \$ 100 \text { s assumed. As of December } 2002 \text {, the actual } \\
\text { quantity of } \$ 100 \text { s in circulation was figure was } \$ 458.6 \text { billion. } \\
\text {. . Not applicable. } \\
\text { Source: Federal Reserve Bank of New York; U.S. Treasury }\end{array}$} \\
\hline
\end{tabular}

We believe that a counterfeit arriving at a foreign bank is less likely than a counterfeit arriving at a U.S. bank to be delivered to the Secret Service or to make it into a Federal Reserve deposit for two reasons. First, U.S. banks are much more likely than their foreign counterparts to contact the Secret Service directly. Second, on average, overseas banks appear to check their dollar shipments more carefully for counterfeits than do U.S. banks, partly because labor costs are generally so much lower in many foreign countries with heavy dollar traffic. As a result of 
the higher level of screening abroad, the incidence of counterfeits from foreign deposits is just over half of that for domestic deposits in recent years. ${ }^{21}$

Table 3 displays lower-bound estimates of the stock of lower-denomination counterfeits in circulation based on Federal Reserve processing data. The Federal Reserve does not provide a the same domestic-foreign breakdown for these denominations, but, based on the $\$ 100$ s data, it is safe to say that the detection rates for lower denominations held overseas should be at or below the domestic levels, making these estimates likely on the high side.

\begin{tabular}{c|c|c|c}
\hline \hline \multicolumn{4}{c}{ Table 3} \\
$\begin{array}{c}\text { Counterfeit \$50, \$20, \$10, \$5, and \$1 Stocks Implied by 2002 Federal Reserve } \\
\text { Processing Data Assuming All Currency Held Within the United States }\end{array}$ \\
\hline Denomination & $\begin{array}{c}\text { Value of genuine } \\
\text { Detection rate } \\
\text { (notes per million) }\end{array}$ & $\begin{array}{c}\text { Votes in circulation } \\
\text { (billions of dollars) }\end{array}$ & $\begin{array}{c}\text { Implied counterfeits } \\
\text { (millions of dollars) }\end{array}$ \\
\hline$\$ 50$ & 5.1 & 58.5 & $\$ 0.30$ \\
$\$ 20$ & 4.7 & 103.7 & $\$ 0.49$ \\
$\$ 10$ & 11.6 & 14.9 & $\$ 0.17$ \\
$\$ 5$ & 4.2 & 9.3 & $\$ 0.04$ \\
$\$ 2$ & 1.1 & 1.2 & $\$ 0.00$ \\
$\$ 1$ & 0.7 & 7.8 & $\$ 0.01$ \\
\hline Total & $\ldots$ & 195.3 & $\$ 1.00$ \\
\hline
\end{tabular}

... Not applicable.

Source: Federal Reserve Bank of New York; U.S. Treasury

It is interesting to note that the incidence of counterfeits detected in processing is substantially lower for the lower denominations than it is for $\$ 100$ s. We believe that the lower incidence can be explained by the overall lower quality of lower-denomination counterfeits.

21 See table 7.2 in U.S. Treasury 2003. 
Lower-quality counterfeits are easier to detect and are thus more likely to be detected before they are returned to a Federal Reserve Bank. Table 4 displays Secret Service data on counterfeits passed in the United States by denomination and method of production. "Circular" notes are those that are assigned classification numbers by the U.S. Secret Service for further investigation. They are typically of higher quality than the other categories of counterfeit notes, which include those printed on office copiers or computer printers or other relatively crude methods.

\begin{tabular}{|c|c|c|c|c|}
\hline \multicolumn{5}{|c|}{$\begin{array}{c}\text { Table } 4 \\
\text { Counterfeits Passed in the United States by Denomination and Method of } \\
\text { Production, Fiscal Year } 2002\end{array}$} \\
\hline Denomination & Circular & $\begin{array}{l}\text { Other (Printer, } \\
\text { Copier, } \\
\left.\text { Raised }{ }^{* *}\right)\end{array}$ & Total & $\begin{array}{c}\text { Circular Share } \\
\text { of Total }\end{array}$ \\
\hline$\$ 100$ & $\$ 22,995,600$ & $\$ 8,263,500$ & $\$ 31,259,100$ & $73.6 \%$ \\
\hline$\$ 50$ & $\$ 402,750$ & $\$ 1,689,650$ & $\$ 2,092,400$ & $19.2 \%$ \\
\hline$\$ 20$ & $\$ 186,420$ & $\$ 5,500,720$ & $\$ 5,687,140$ & $3.3 \%$ \\
\hline$\$ 10$ & $\$ 28,470$ & $\$ 1,033,740$ & $\$ 1,062,210$ & $2.7 \%$ \\
\hline$\$ 5$ & $\$ 2,345$ & $\$ 160,870$ & $\$ 163,215$ & $1.4 \%$ \\
\hline$\$ 2$ & $\$ 0$ & $\$ 114$ & $\$ 114$ & $0.0 \%$ \\
\hline$\$ 1$ & $\$ 535$ & $\$ 14,425$ & $\$ 14,960$ & $3.6 \%$ \\
\hline Total ${ }^{*}$ & $\$ 23,616,120$ & $\$ 16,663,019$ & $\$ 40,279,139$ & $58.6 \%$ \\
\hline \multicolumn{5}{|c|}{$\begin{array}{l}\text { *Excludes denominations above } \$ 100 \text {. } \\
* * \text { Raised notes are high-denomination counterfeits that are constructed from genuine } \\
\text { lower-denomination notes. For example, raised notes often feature one or more corners } \\
\text { of a high-denomination note attached to the body of a lower denomination note. } \\
\text { Source: U.S. Secret Service }\end{array}$} \\
\hline
\end{tabular}

The data in Table 4 indicate that circular notes are nearly three quarters of $\$ 100$ counterfeits passed, but less than one fifth of $\$ 50$ counterfeits passed and less than 5 percent of $\$ 20$ and smaller counterfeits passed. At the domestic consumer level, the breakdown between 
circular and other notes is significant. A non-circular counterfeit note is usually of minimal quality: a person with minimal training in counterfeit detection and currency authentication should be able to detect it readily with the naked eye, and successful passing occurs only when the recipient of the note fails to give it much scrutiny at all. Over 95 percent of the notes in the $\$ 20$ and smaller denominations, which are those most commonly used by U.S. consumers, fall into the non-circular category. The implication for most U.S. residents is that a minimal level of vigilance is enough to virtually rule out losses from counterfeiting: as can be seen from Table 4 , the value of circular counterfeits passed in the $\$ 20$ and smaller denominations in 2002 was less than $\$ 220,000$.

\subsection{Using Federal Reserve and Secret Service Data to Estimate the Total Stock of Counterfeits in Circulation}

We now return to the estimate of the total stock of counterfeits. As noted above, a lower bound for the estimate of $\$ 100$ counterfeits in circulation is $\$ 11$ million to $\$ 13$ million and a lower bound for the number of other denominations in circulation is $\$ 1$ million, for a total of $\$ 12$ to $\$ 14$ million. Within the United States, about five or six counterfeit $\$ 100$ notes are detected outside the Federal Reserve for each note found by the Federal Reserve. An estimate of total counterfeit $\$ 100$ s in circulation based on such ratios would be about $\$ 66$ million ( $\$ 11$ million multiplied by 6) to $\$ 98$ million ( $\$ 13$ million multiplied by 7 ). For the lower denominations, the ratio of notes found outside the Federal Reserve to those found inside ranges from seven or eight to one for $\$ 50$ s to less than one for one for $\$ 1 \mathrm{~s}$, as shown in Table 5 ; these findings generates a range of $\$ 1$ million to $\$ 9$ million for the estimated stock of smaller-denomination counterfeits in circulation. Thus, the range of estimates for the total quantity of counterfeits in circulation 
becomes $\$ 67$ million to $\$ 108$ million.

This range, however, should be viewed as an upper bound, for reasons similar to those discussed above. The counterfeits found outside the Federal Reserve are generally of lower quality and more easily detected (hence their detection outside the Federal Reserve). Thus, they likely do not circulate for as long as the counterfeits that survive until reaching the Federal Reserve. ${ }^{22}$ Since we believe that both the upper-bound and lower-bound estimates are relatively far from the true stock of counterfeits in circulation, a middle-range value of about $\$ 40$ to $\$ 50$ million, or less than $\$ 1$ worth of counterfeit for every $\$ 10,000$ in circulation, is most likely.

\begin{tabular}{|c|c|c|c|c|}
\hline \multicolumn{5}{|c|}{$\begin{array}{c}\text { Table } 5 \\
\text { Counterfeits Passed in the United States in } 2002 \\
\text { By Denomination and Source } \\
\text { Pieces }\end{array}$} \\
\hline $\begin{array}{c}\text { Denomin } \\
\text { ation }\end{array}$ & $\begin{array}{c}\text { FRB } \\
\text { Passed }\end{array}$ & $\begin{array}{c}\text { Non FRB } \\
\text { Passed } \\
\end{array}$ & Total Passed & $\begin{array}{l}\text { FRB } \\
\text { Share }\end{array}$ \\
\hline$\$ 1$ & 9,293 & 7,700 & 16,994 & $55 \%$ \\
\hline$\$ 2$ & 18 & 42 & 62 & $30 \%$ \\
\hline$\$ 5$ & 11,050 & 21,842 & 32,897 & $34 \%$ \\
\hline$\$ 10$ & 25,389 & 82,482 & 107,881 & $24 \%$ \\
\hline$\$ 20$ & 68,883 & 215,873 & 284,776 & $24 \%$ \\
\hline$\$ 50$ & 5,665 & 36,397 & 42,112 & $13 \%$ \\
\hline$\$ 100$ & 49,352 & 263,651 & 313,103 & $16 \%$ \\
\hline Total & 169,650 & 627,987 & 797,637 & $21 \%$ \\
\hline
\end{tabular}

Source: U.S. Secret Service

${ }^{22}$ Appendix B in U.S. Treasury (2000) takes up the issue of the lifespan of a counterfeit. 


\section{How Representative Are Our Datasets? Comparing the Datasets}

\subsection{Country-Level Comparisons}

In principle, the country-by-country Federal Reserve Cash Office processing data on counterfeits should be a subset of the Secret Service data. Under certain conditions, moreover, the proportions of counterfeits detected by country and region should be similar in both datasets. However, neither of these conditions holds exactly in the data we present here and as a result, the ratios do not exactly coincide, though most observations do fall within two standard deviations of the mean absolute deviation.

There are two conditions that would need to hold for the country-specific counterfeit datasets to exactly match both each other and the underlying true country distribution of counterfeits. First, the Secret Service's ability to detect counterfeits would have to be exactly uniform across countries. This condition is surely not the case given variation in staff size, relations with local law enforcement, and other local factors. Second, the notes processed by the Federal Reserve would have to be a random sample of the notes in circulation in a given country. This condition is somewhat more likely to hold. While some currency is held for long periods and some currency is selected for return to the United States because it is extremely worn or dirty, our estimates below on hoarding suggest that notes circulate fairly randomly.

The Secret Service data used here cover only notes passed to the public in fiscal year 2002; they do not include notes seized, since these notes by definition were never in circulation. Since the Secret Service dataset includes counterfeits found by the Federal Reserve, the Secret Service's figure for each country should exceed the Federal Reserve's figure. Countries are 
dropped if the Secret Service shows fewer counterfeits than the Federal Reserve.

Each point in Figure 1 represents one country's share of the counterfeits detected in each data set. Thus, a point at $(5,10)$ would indicate that 5 percent of the counterfeits detected at the New York Federal Reserve Cash Office came from that country while 10 percent of the counterfeits detected by the Secret Service did. These points would all lie on the 45-degree line if the relative detection rates between the two data sets agreed and if the samples of notes processed were exactly representative of the notes in circulation. The dotted lines represent a 95 percent confidence interval around the 45-degree line. Since all of the points associated with the individual country pairs lie within the confidence band, we cannot reject the hypothesis that the relative detection rates in the two datasets are not significantly different from one another. 
Figure 1

Shares of Counterfeits Found in Various Countries, FY 2002 (shares in percent)

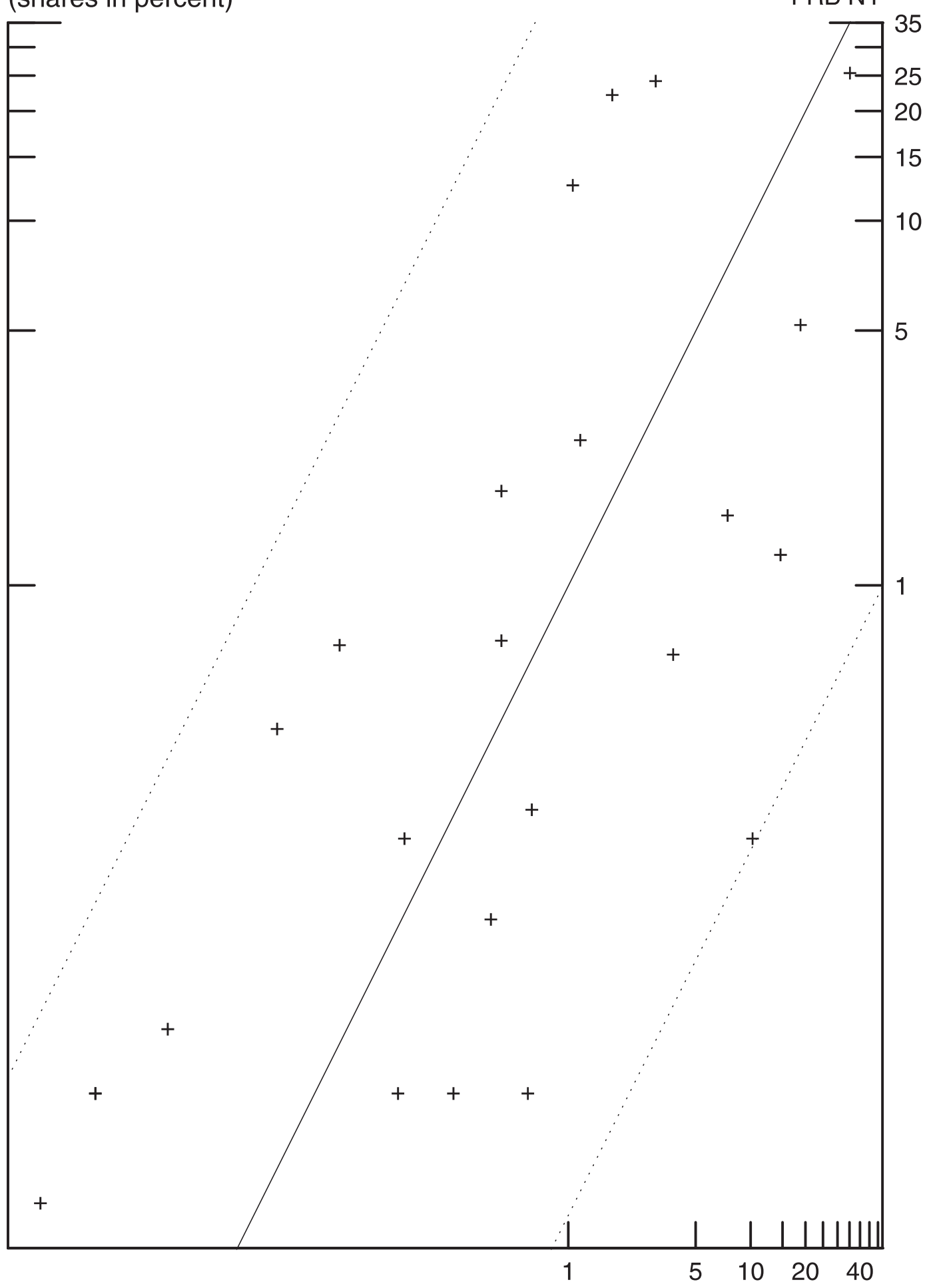

U.S. Secret Service 


\subsection{Secret Service Data and Counterfeit Stock Estimates}

We now return to the estimate of the total stock of counterfeits. Recall that extrapolation from Federal Reserve cash processing data yields an estimated stock of \$12-\$14 million in counterfeits of all denominations in circulation. In contrast, the Secret Service data for 2002 indicate that the total value of counterfeit currency passed on the public in 2002 was about $\$ 41.5$ million, roughly three to three and a half times what the Federal Reserve data would suggest, but in the range of our "mid-range" estimate and well below our upper bound. It is not clear what this discrepancy implies. Most notably, we do not know how long a typical counterfeit circulates before being detected. If, for example, the average counterfeit only circulated for one month before being detected, then the annual Secret Service statistics could be consistent with as little as $\$ 3.5$ million in counterfeit currency circulating at any given time. ${ }^{23}$ Thus, if we were willing to assume that the Secret Service on average finds counterfeits within a three or four months of their first appearance, the Federal Reserve and Secret Service figures would be consistent with each other.

In fact, our circulation data can help resolve this issue. Assume first that we are in counterfeit equilibrium in which the stock of counterfeits as a share of genuine currency in circulation is roughly constant. Then the number of counterfeits that is detected and removed from circulation each year should be roughly equal to the number that are placed into

\footnotetext{
${ }^{23}$ That is, if each month $\$ 3.5$ million in counterfeits entered circulation, were then detected by the Secret Service in that month, and were then replaced with new counterfeits, the Secret Service could find $\$ 3.5$ million $\times 12=\$ 42$ million in counterfeit currency each year even though at any moment only $\$ 3.5$ million was in circulation.
} 
circulation. ${ }^{24}$ The questions are then how fast the stock of counterfeits turns over and what share of total counterfeits detected are reported to the Secret Service.

Consider the circulation lives of $\$ 100$ notes. Genuine notes circulate, return to Reserve Banks, and sometimes recirculate; their average lifespan is about eight years. ${ }^{25}$ In contrast, counterfeits end their lives when they are detected, which at the very latest is on their first (and only) trip to a Federal Reserve Cash Office. Cash processing data from the first year following the introduction of the 1996-series $\$ 100$ note indicate that about one-third of the total notes outstanding at the beginning of the period were replaced, which means that one-third of the notes visited the Federal Reserve at least once. If counterfeits circulate at least as fast as genuine notes, which we benchmark with observations on $\$ 100$ s after the introduction of the 1996-series notes, then on average counterfeits should remain in circulation at most about three years before facing certain detection at a Federal Reserve Bank. However, the average lifespan of a counterfeit $\$ 100$ is probably only a small fraction of three years for three reasons. First, as noted earlier, more than 80 percent of $\$ 100$ counterfeits are detected prior to reaching a Federal Reserve Bank. ${ }^{26}$ Second, we have reason to believe that, if anything, counterfeits circulate faster

${ }^{24}$ More precisely, assuming that counterfeits represent a constant percentage of currency in circulation, the number of new counterfeits entering circulation would be equal to the number of counterfeits leaving circulation multiplied by the overall growth rate of currency in circulation.

${ }^{25}$ The estimate is probably on the high side. A 1991 Federal Reserve survey found such an estimate but the rate at which $\$ 100$ s has been received from circulation has increased significantly since then, suggesting an average age more in the neighborhood of 5 years might be more appropriate now.

${ }^{26}$ As seen in Table 5, in calendar year 2002, Federal Reserve Banks 16 percent of all counterfeit $\$ 100$ s passed. 
than genuine notes: all other things equal, if an individual has two notes and considers one of them "suspicious" or possibly counterfeit, the individual is likely to try to get rid of that note first. Thus, we assume that on average counterfeits could remain in circulation at most for one year, with a few months being much more likely. ${ }^{27}$

Table 6: Stocks of \$100 Counterfeits for Various Longevity and Share Abroad Assumptions

(\$ Million)

\begin{tabular}{|c|c|c|c|c|}
\hline Longevity & $\begin{array}{c}\text { Implied } \\
\text { Counterfeits in } \\
\text { U.S. } \\
\text { (\$ million) } \\
\end{array}$ & $\begin{array}{c}\text { Share of } \\
\text { Genuine Notes } \\
\text { Abroad }(\%)\end{array}$ & $\begin{array}{c}\text { Implied } \\
\text { Counterfeits } \\
\text { Abroad } \\
\text { (\$ million) } \\
\end{array}$ & $\begin{array}{c}\text { Implied Total } \\
\text { Counterfeits } \\
\text { (\$ million) }\end{array}$ \\
\hline \multirow[t]{2}{*}{1 month } & \multirow[t]{2}{*}{3} & 50 & 3 & 5 \\
\hline & & 70 & 6 & 9 \\
\hline \multirow[t]{2}{*}{3 months } & \multirow[t]{2}{*}{8} & 50 & 8 & 16 \\
\hline & & 70 & 18 & 26 \\
\hline \multirow[t]{2}{*}{6 months } & \multirow[t]{2}{*}{16} & 50 & 16 & 31 \\
\hline & & 70 & 37 & 52 \\
\hline \multirow[t]{2}{*}{1 year } & \multirow[t]{2}{*}{31} & 50 & 31 & 63 \\
\hline & & 70 & 73 & 104 \\
\hline
\end{tabular}

Counterfeit $\$ 100$ s detected within the U.S. by the Secret Service in 2002: \$31 million

Next, the question is what share of notes that are detected as counterfeit appear in the Secret Service's statistics. For domestic notes, this figure is almost surely near 100 percent. For counterfeits detected overseas, this figure is surely well below 100 percent, but whether it is 10

${ }^{27}$ Appendix B.2 in U.S. Treasury (2000) addresses this issue in more detail. In informal discussions, agents from the U.S. Secret Service have repeatedly noted that their investigations point to very short active lives for counterfeits in active circulation; they consider one year to be beyond a reasonable upper bound for the average lifespan of a counterfeit note. Based on the calculations in U.S. Treasury (2000) and the input from the U.S. Secret Service, we would place the probability that the true average lifespan of a counterfeit dollar exceeds a year at well 
percent or 70 percent is difficult to say. In any case, using domestic figures as a benchmark, we know that about $\$ 31$ million worth of $\$ 100$ notes was recorded as passed in fiscal year 2002 . Using the figure of an average lifespan of a counterfeit note of one year and the assumption of constant shares of counterfeit activity, we arrive at an estimate of domestic steady-state stock of counterfeit $\$ 100$ s of about $\$ 31$ million.

We can extrapolate to the rest of the world in a couple of directions; Table 6 presents the calculations. Depending on how much of the stock of $\$ 100$ s we assume is held outside the United States and how long we think the average counterfeit $\$ 100$ survives before being detected, there could be anywhere from $\$ 5$ million to $\$ 104$ million in counterfeit $\$ 100$ s outstanding. These calculations rest critically on the assumption of the lifespan of a counterfeit. As noted above, we consider the one-year assumption to be a very realistic or conservative upper bound.

Table 7 displays the results of similar calculations for $\$ 20$ s. We have not formally estimated how many $\$ 20$ s are in circulation outside the United States, but we consider 50 percent to be a reasonable upper bound. In addition, $\$ 20$ s circulate much more rapidly than $\$ 100$ s: in 2002 , about three times as many $\$ 20$ s were processed by Federal Reserve Banks as were in circulation, so on average a $\$ 20$ circulates for only a few months before certain detection at a Federal Reserve Bank. The average life of a counterfeit \$20 is likely even shorter than a few months, but we show the same range of time possibilities as for $\$ 100$ s just for comparison. The results for $\$ 20$ s, as for $\$ 100$ s, have a very wide range, but the value is substantially lower: from

below 1 percent. 
less than $\$ 1$ million to about $\$ 11$ million. Note that the upper bound estimate of $\$ 11$ million amounts to 1 counterfeit $\$ 20$ note for every 10,000 notes in circulation. Since the volume of counterfeiting among the remaining denominations is in a range similar to or much smaller than that of $\$ 20$ s, we omit tables for those denominations.

\begin{tabular}{|c|c|c|c|c|}
\hline Longevity & $\begin{array}{c}\text { Implied } \\
\text { Counterfeits in } \\
\text { U.S. } \\
\text { (\$ million) } \\
\end{array}$ & $\begin{array}{c}\text { Share of } \\
\text { Genuine Notes } \\
\text { in U.S. }(\%)\end{array}$ & $\begin{array}{c}\text { Implied } \\
\text { Counterfeits } \\
\text { Abroad } \\
\text { (\$ million) } \\
\end{array}$ & $\begin{array}{c}\text { Implied Total } \\
\text { Counterfeits } \\
\text { (\$ million) }\end{array}$ \\
\hline \multirow[t]{2}{*}{1 month } & \multirow{2}{*}{0.5} & 5 & 0.0 & 0.5 \\
\hline & & 50 & 0.5 & 0.9 \\
\hline \multirow[t]{2}{*}{3 months } & \multirow[t]{2}{*}{1.4} & 5 & 0.1 & 1.5 \\
\hline & & 50 & 1.4 & 2.8 \\
\hline \multirow[t]{2}{*}{6 months } & \multirow[t]{2}{*}{2.8} & 5 & 0.1 & 3.0 \\
\hline & & 50 & 2.8 & 5.7 \\
\hline \multirow[t]{2}{*}{1 year } & \multirow[t]{2}{*}{5.7} & 5 & 0.3 & 6.0 \\
\hline & & 50 & 5.7 & 11.4 \\
\hline
\end{tabular}

Counterfeit $\$ 20$ s detected within the U.S. by the Secret Service in 2002: \$5.7 million

We now return to our comparisons of Federal Reserve and Secret Service data. Recall that the Secret Service found about twice as many notes as the Federal Reserve data would suggest are outstanding. This finding is consistent with either a lifespan of just a few months for the average counterfeit, or with a longer lifespan for each note and more detection outside the Federal Reserve, or with some combination of these two factors, which we believe to be the case. We do consider the range of estimates to be bounds on the true number of counterfeits in circulation at a given time: the two data sources on counterfeits, plus what we know about 
circulation, suggest that it is very unlikely that more than $\$ 31$ million in counterfeit $\$ 100$ s is in circulation within the United States. Extrapolation to the stock of notes circulating outside the United States is similarly ambiguous, but does yield an upper bound figure of \$104 million. Estimates for \$20s would add \$11 million to that total, and estimates for the remaining denominations would add at most another $\$ 10$ million, for a total of at the very most $\$ 125$ million for all notes in circulation. Note that this figure, which we consider to be extremely conservative (i.e., very much on the high side of the truth) still represents less than 1/50 of one percent of all currency in circulation.

\section{The Next Step: How Unrepresentative Are Our Data?}

The estimates constructed above rely heavily on the assumption that currency, both genuine and counterfeit, circulates with some frequency, which we generally believe to be true. ${ }^{28}$ However, it is sometimes asserted that counterfeit notes somehow find their way into isolated "pools" of currency that never reach the banking system.

Below we present two models that show why it is unlikely that notes can remain outside the banking system indefinitely. The first model shows that notes in active circulation almost surely return to the banking system after a relatively small number of transactions, which on average translates into a relatively short period. The second model exploits cash processing data to estimate the shares of currency at home and abroad that might be hoarded, or out of circulation for more than a year at a time. Both of these models suggest that it is extremely

${ }^{28}$ Counterfeit currency likely circulates more rapidly than genuine currency, but with rare exceptions, all currency moves into the market occasionally. 
unlikely that large quantities of counterfeits that have been passed can hide anywhere for very long.

\subsection{Hoarding}

In some countries and circumstances, U.S. dollars are used as a store of value and can be held for a very long time without circulating. We exploit the processing data from the Federal Reserve Cash Offices to estimate the parameters of a simple model of hoarding. In this model, a share $h$ of the currency stock is hoarded in a given year, and a share $\alpha$ of the hoarded stock is turned over every year. The currency processed is a random sample of the active notes only. The key ingredient in this model is the fact that a new-series $\$ 100$ note was introduced in 1991. After this date, all old-series $\$ 100$ s arriving at Cash Offices were replaced with new-series notes. We have six years of data, 1991-1996, and two unknowns, $h$ and $\alpha$. If the population of notes is $n$ and notes are drawn (processed) randomly with replacement, then the probability that a note gets processed in one draw is $1 / n$. The probability that a note is drawn after $p$ draws is thus

$$
1-\left(1-\frac{1}{n}\right)^{p}
$$

Observe that the only notes that can be processed are in the active share of the pool, $A$. Thus, the right figure to use in the denominator of the equation above is not $n$ but $A n$. Since the draws are independent, the number of notes replaced, say $r$, is just equal to $A n$ times the probability that one note will be replaced:

$$
r=\operatorname{An}\left(1-\left(1-\frac{1}{n}\right)^{p}\right)
$$

Dividing both sides by $n$, we obtain an expression in terms of $R$, the share of notes 
replaced, as a function of $A$, the active share of the population, $n$, the total note population, and $p$, the number of notes processed. This is our basic equation:

$$
R_{t}=A\left(1-\left(1-\frac{1}{n_{t}} \frac{1}{A}\right)^{p_{t}}\right)
$$

The stock of $\$ 100$ s outstanding grew fairly rapidly in this period. We assume, however, that the share of notes hoarded remained constant. After the first year, $R$ is defined net of note growth. Moreover, one must account for the fact that some notes enter the active pool and some leave. If $\alpha$ is the share of inactive notes that re-enter the active pool each period, $R$ after the first period is defined as

$$
R_{t>1} \equiv\left(I-G n_{t}\right)\left(\frac{1}{m^{a}}\right)
$$

where I is the number of new notes issued, $G$ is the growth rate of the stock of notes, and $\mathrm{m}^{\mathrm{a}}$ and $\mathrm{m}^{\mathrm{h}}$ are active and hoarded stocks of new-series notes, with $\mathrm{m}^{\mathrm{a}}$ defined as follows:

$$
m_{t}^{a} \equiv m_{t}-m_{t}^{h} \equiv m_{t}-\left(m_{t-1}^{h}-\alpha m_{t-1}^{h}+\alpha\left(1+G_{t}\right)\left(\frac{m_{t} / n_{t}}{A}\right)\right.
$$

Since there are two parameters, we conduct a grid search to find the best fit. We estimate the parameters separately for notes circulating within and outside the United States. Since we do not know the total number of notes circulating in each area, we estimated the parameters for a range of assumptions about the share of notes held abroad. As in previous work (Porter and Judson, 1996), we treated the New York Cash Office as the "foreign" office since we know that it handles the bulk of foreign shipments.

The objective functions are well-behaved but fairly flat. In general, they indicate that hoarding is unlikely to be important for very long, and that turnover is likely to be high. For 
example, for the case of fifty percent of currency stocks assumed abroad, we find that $\alpha$, the turnover rate for inactive currency, is 0.6 for domestic currency and 0.99 (corner solution) for overseas dollars. We find that the share hoarded at home is 0.19 and is effectively zero (again a corner solution) overseas. ${ }^{29}$ For other assumptions, the highest share of hoarding found is 0.69 and the lowest turnover is 0.47 . We conclude that it is highly unlikely that large quantities of notes are likely to stay out of circulation (and hidden from counterfeit detection) for very long.

\section{2 "Pools" of Undetected Counterfeits}

One often-cited possibility is that there are isolated "pools" of circulating currency with high concentrations of counterfeits that do not circulate to Cash Offices. Although such an idea is in principle plausible, we are able to show that it is in practice highly unlikely.

This idea that notes could circulate outside the banking system indefinitely is based on several assumptions, including some variation on the following:

(a) Currency overseas endlessly recirculates without being processed by any banking entity, thus counterfeit is not detected and continues to circulate, or

(b) Currency is processed by banking entities that lack detection capability, thus counterfeit is not detected and continues to circulate, or

\footnotetext{
${ }^{29}$ At first blush, it might seem counterintuitive that overseas notes emerge from the hoarding state with a greater propensity abroad. A 1989 survey of notes circulating domestically and internationally found that the turnover rates of foreign and domestic notes were similar in that they had similar age-degree of use profiles where use was measured by the quality and degree of soil on the notes. Such a pattern indicates that the notes were active to about the same degree both domestically and overseas. Since currently a large portion of United States is held abroad in rather undeveloped economies where currency is used extensively, the turnover rate may be higher abroad simply because currency is a relatively more important source of
} 
(c) Currency is processed by banking entities that detect the counterfeit, but choose to recirculate the currency to avoid losses, thus counterfeit continues to circulate,

(d) Currency continues to circulate overseas without routinely being repatriated, thus counterfeit is not detected and continues to circulate.

When we visited central and commercial banks and authorities charged with stopping counterfeiting in a large group of countries, we were able to observe counterfeit detection capabilities and the condition of the currency. Based on what we observed, it was apparent that currency does not endlessly recirculate in any of the markets we visited. Currency is used for a wide range of transactions, but even in gray or black market economies it will eventually find its way into a commercial banking institution, most likely after being used in relatively few transactions. $^{30}$

The logic behind our conclusion that notes cannot remain in circulation very long is readily laid out. Since transactions are usually between unrelated individuals, it is plausible to assume that successive transactions are statistically independent of one another. To make the

payment than in the United States and therefore used more often.

${ }^{30}$ There is an important exception to this argument. For years, stories have circulated that some government(s) hostile to the United States had obtained plates to print currency and were going to produce a flood of counterfeits in an effort to destabilize the dollar. It was argued that these counterfeits could circulate endlessly and freely within the bounds of such countries. We have no way of confirming or denying such stories. If "closed" countries (e.g., North Korea) do indeed have many counterfeits in circulation, it is impossible to know as long as the system remains closed. The evidence and model we present here apply to open markets and economies. Moreover, in a closed system where nobody is being fooled about the genuineness (or lack thereof) of the currency, it is not clear that there is a loss to consumers and, as long as the counterfeits remain confined to the closed economy, they do not affect the value of genuine dollars. 
analysis tractable, also assume that there is a constant probability, say $\mu$, that after any transaction a given banknote will not be returned to a financial institution. There is a presumption that $\mu$ should be relatively small. After all, apart from transactions between individuals, most currency transactions are with retail establishments and most retailers generally accumulate nearly all of the currency they receive and deposit/sell all but "seed" cash -- in particular, all large-denomination notes -- at financial institutions or exchange houses on at least a daily basis. Survey evidence suggests that currency circulating both within and outside the United States turns over (is exchanged) on average about once a week. ${ }^{31}$ If the probability is $\mu$ that the note recirculates, the note is used in one transaction per week, and successive transactions are independent, the probability that the note will continue to recirculate after $\theta$ weeks has a joint binomial distribution with probability $\mu^{\theta}$. Thus, the complementary event that a given note is returned to a financial institution after $\theta$ transactions is $1-\mu^{\theta}$. Clearly, this probability will approach unity after a relatively short interval of time even if $\mu$ is close to unity because it is raised to the power $\theta$. For example, consider the extreme case where $\mu=0.9$ so the odds are 9 to 1 that a note will recirculate; even in this case after 7 weeks, the probability is greater than one half that the note will hit the banking system; and after 22 weeks, the probability is greater than 0.95 that the note will stop recirculating. A more plausible assumption would be to assume $\mu=0.1$ so that most transactions are with retail vendors and not with "hand-to-hand transactors." In this case, the probability that the note will be returned to a financial institution approaches one almost immediately.

\footnotetext{
${ }^{31}$ See Porter and Judson (1996) and Feige (1996).
} 
If notes turn over more frequently than one time per week, the time of the first passage to the financial institution would be even sooner. In some countries, cash dollars are the dominant medium of exchange even for small daily purchases; in this case, notes could turnover as fast as once per day on average. If currency turned over on a daily basis, the twenty-two week period for the first passage of a note to a financial institution in the extreme case with $\mu=0.9$ would be cut to one-seventh of the time, or approximately three weeks.

Once currency hits the banking system, it naturally flows to regional financial processing centers, and is routinely repatriated in large quantities. Thus, currency does not generally recirculate in large amounts, most probably not in amounts any greater than is found in Federal Reserve deposits from foreign sources. Further, it is quite unlikely that banks recirculate counterfeits either to other banks or to their customers. While the bank pays no additional penalty if another bank or the Federal Reserve finds a counterfeit, its reputation can suffer if customers find the bank giving out counterfeits.

In sum, we find it unlikely that counterfeits can circulate for long outside the banking system, and thus outside reasonably sophisticated counterfeit detection, for very long. These figures thus suggest that notes are unlikely to circulate outside banks for much more than a year.

\section{Conclusion}

We develop upper and lower bound estimates for the quantity of counterfeit dollars in circulation. Processing data from the Federal Reserve Bank of New York suggest a lower bound of $\$ 12$ to $\$ 14$ million in value terms. Using denomination-specific weights to scale up the lower- 
bound estimate to account for the counterfeits passed outside the Federal Reserve yields an upper-bound estimate of $\$ 67$ to $\$ 108$ million, or about $\$ 1$ to $\$ 1.50$ per $\$ 10,000$ in circulation. We believe that an estimate in the neighborhood of $\$ 40$ to $\$ 50$ million, or 60 to 80 cents per $\$ 10,000$ in circulation, is the most plausible, and is consistent with a relatively short average lifespan for a given counterfeit note. These figures are relatively small, but for U.S. consumers, the threat from high-quality counterfeits is even smaller: for the $\$ 20$ and smaller denominations, counterfeiting losses are tiny, at $\$ 7$ million in 2002 , of which less than $\$ 220,000$ were notes that could not be detected by users with minimal hand inspection.

We further find that while it is indeed possible that a large number of counterfeits could be injected into the financial system, it is quite unlikely that they would remain there in use and undetected. We find the close correlation between the country distribution of the counterfeits detected by the Federal Reserve and the Secret Service particularly intriguing; we believe it is strong evidence that both counterfeit detection and incidence fall within a small range of about one note in 10,000 throughout countries where dollars are in circulation. 


\section{References}

Allison, Theodore E. and Rosanna S. Pianalto, "The Issuance of Series-1996 \$100 Federal Reserve Notes: Goals, Strategies, and Likely Results," Federal Reserve Bulletin 83:7 (July 1997), pp. 557-564.

American Bankers Association. “ABA Deposit Account Fraud Survey Report 2002." Washington, D.C.: American Bankers Association, 2002.

Board of Governors of the Federal Reserve System, "Report to Congress on Funds Availability Schedules and Check Fraud at Depository Institutions", October 1996.

Economic Report of the President. Washington, D.C.: United States Government Printing Office, 2003.

Feige, Edgar L., "Overseas Holdings of U.S. Currency and the Underground Economy," in Susan Pozo, ed., Exploring the Underground Economy: Studies of Illegal and Unreported Activity (Kalamazoo, Michigan: W.E. Upjohn Institute for Employment Research, 1996), pp. 5-62.

Green, Edward J., and Warren E. Weber, "Will the New \$100 Bill Decrease Counterfeiting?" Federal Reserve Bank of Minneapolis Quarterly Review, Summer 1996, pp. 3-10.

Judson, Ruth A., and Richard D. Porter, "Overseas Dollar Holdings: What Do We Know?" Wirtschaftspolitische Blatter 4 /2001.

Lengwiler, Yvan, "A Model of Money Counterfeits," Journal of Economics 65:2 (1997), pp. 123-132.

Parke, Darrel, and Laura Parker Gilles, A Comprehensive Assessment of U.S. Currency Quality, Age, and Cost Relationships (Washington, D.C.: Federal Reserve System), September 1991.

Porter, Richard D. and Ruth A. Judson, "The Location of U.S. Currency: How Much is Abroad?" Federal Reserve Bulletin 82:10 (October 1996), pp. 883-903. Addendum to the Treasury Audit Plan on the Uses and Counterfeiting of U.S. Currency, April 1997, Department of the Treasury.

Porter, Richard D., "Estimates of Foreign Holdings of U.S. Currency-An Approach Based on Relative Cross-Country Seasonal Variations," in Nominal Income Targeting with the Monetary Base as Instrument: An Evaluation of McCallum's Rule, Finance and Economics Discussion Series Working Study 1 (Board of Governors of the Federal Reserve System, March 1993). 
, "Foreign Holdings of U.S. Currency," International Economic Insights (November/December 1993), p. 5.

and Ruth A. Judson, "The Location of U.S. Currency: How Much is Abroad?" Federal Reserve Bulletin 82:10 (October 1996), pp. 883-903.

Porter, Richard D., and Gretchen C. Weinbach, "Currency Ratios and U.S. Underground Activity," Economics Letters 63:3 (June 1999), pp. 355-361.

U.S. Department of the Treasury, The Use and Counterfeiting of U.S. Currency Abroad (February 2000).

U.S. Department of the Treasury, The Use and Counterfeiting of U.S. Currency Abroad, part 2 (March 2003). 